\title{
Towards a DIAMEX process using high active concentrate. Production of genuine solutions
}

\author{
By D. Serrano-Purroy ${ }^{1, *}$, B. Christiansen ${ }^{1}$, J.-P. Glatz ${ }^{1}$, R. Malmbeck ${ }^{1}$ and G. Modolo ${ }^{2}$ \\ ${ }^{1}$ European Commission, JRC, Institute for Transuranium Elements, Postfach 2340, 76125 Karlsruhe, Germany \\ 2 Forschungszentrum Jülich GmbH, Institute for Safety Research and Reactor Technology, 52425 Jülich, Germany
}

(Received November 18, 2004; accepted in revised form February 3, 2005)

\section{High active concentrate / Concentration-denitration / DIAMEX}

Summary. The efficiency of Minor Actinides (MA) recovery in the DIAMEX process has already been demonstrated using High Active Raffinate (HAR). The next step aims at the demonstration of reprocessing from High Active Concentrate (HAC) as feed, in view of an industrial application. The volume reduction would reduce the size of the installation to be used and thereby the costs of the process. The first step towards the demonstration of a DIAMEX process using HAC is the production of the genuine solutions. In the hot cell facility of ITU (Institute for Transuranium Elements), a HAR solution has been prepared, from small scale PUREX reprocessing of MOX fuel, and successfully subjected to a concentration/denitration process to obtain HAC. A final concentration factor $(\mathrm{CF})$ of about 10 and an acidity of $4 \mathrm{M}$ were reached. In the experiment a precipitate mainly composed of $\mathrm{Sr}, \mathrm{Zr}$, Mo, Sn and Ba was formed. MA precipitation was not significant $(<0.001 \%)$.

\section{Introduction}

Partitioning and transmutation (P\&T) concepts are studied world wide to reduce the long-term radiotoxicity of the nuclear waste, with special focus on MA. Today fissile uranium (U) and plutonium $(\mathrm{Pu})$ are recovered by PUREX reprocessing, leaving the MA's together with the bulk of fission products in the high active liquid waste stream - the socalled high active raffinate (HAR). The present waste management of HAR is concentration and further immobilisation in borosilicate glass blocks for final storage in a deep geological repository. However, the long-term radiotoxicity could be reduced and the waste management of HAR issued from reprocessing could greatly be improved by the removal of MA. New advanced aqueous reprocessing schemes have therefore been developed, aiming primarily at the complete recovery of americium and curium from HAR. The scheme developed in Europe is the combination of the DIAMEX and SANEX processes. In this scheme the trivalent actinides Am and $\mathrm{Cm}(\mathrm{An})$ are co-separated with lanthanides $(\mathrm{Ln})$ in the DIAMEX [1-3] process and the subsequent separation of

\footnotetext{
*Author for correspondence (E-mail: Daniel.Serrano@itu.fzk.de).
}

Am and $\mathrm{Cm}$ from lanthanides is carried out in the SANEX process [3]. The aqueous product fraction (containing Am and $\mathrm{Cm}$ ) can be subjected to a subsequent Am/Cm separation process to provide the possibility for a specific recycling and transmutation of Am and possibly a specific conditioning of $\mathrm{Cm}$.

The efficiency of the DIAMEX process has been demonstrated in hot tests using genuine fuel solutions, produced by in-house small-scale PUREX reprocessing [4]. It has been shown that $99.9 \%$ of the Am and Cm contained in the HAR feed can be recovered by extraction in a 16 stages centrifugal extractor set-up. The next set of experiments aims at the demonstration of MA recovery by the DIAMEX process using high active concentrate (HAC) as feed - in view of an industrial application. The decrease in volume (compared to HAR) would reduce the size of the installation and thereby the costs of the process.

The first step towards the demonstration of a DIAMEX process using $\mathrm{HAC}$ has been the production of genuine starting solutions. This work describes the preparation of genuine HAR by PUREX reprocessing and the subsequent concentration/denitration to obtain a genuine HAC solution.

\section{Experimental}

\section{Reagents}

All reagents and chemicals were of analytical reagent grade. TriButylPhosphate (TBP), dodecane and formic acid were obtained from MERCK (Germany). The nitric acid solutions were prepared either from dilution of concentrated nitric acid or from Titrisol ampoules. MQ grade water $(18 \mathrm{M} \Omega / \mathrm{cm})$ was used for all dilutions. Simulate solutions were prepared from commercially available metal nitrates or from pure metals. The simulate preparation recipe is described elsewhere [5].

\section{Apparatus and experimental procedure PUREX process}

The centrifugal extractor equipment installed in the hot cells is described elsewhere [6]. The PUREX reprocessing was carried out using 16 extractor stages divided in four blocks 
with four extractors each. At the end of the experiment centrifuges and pumps were turned off simultaneously and samples were taken from the mixing chambers of each centrifuge and the two phases were separated. In addition, the feed and the collected fractions were sampled during the last 30 minutes of the experiment.

All concentrations in the aqueous samples were determined by a High Resolution ICP-MS (Thermoelectron Element 2). Samples taken from the organic phase were back-extracted twice with $0.1 \mathrm{M} \mathrm{HNO}_{3}$ (aqueous to organic volume ratio of 2) prior to analyses.

The PUREX process flow-sheet is shown in Fig. 1. The extraction section contains 6 extraction stages followed by 2 scrub stages with a maximum $\mathrm{O} / \mathrm{A}$ volume flowrate ratio of 5, well inside the operational limit of the centrifuges. The loaded organic phase is back-extracted in 8 stages in $0.01 \mathrm{M}$ nitric acid with a reduced $\mathrm{O} / \mathrm{A}$ of 0.83 to obtain efficient stripping. The process scheme was optimised to minimise waste and the organic phase was then reused after hydroxilic conditioning $(1 \mathrm{M} \mathrm{NaOH})$ followed by reacidification (4.5 $\mathrm{M} \mathrm{HNO}_{3}$ ).

In total $1.4 \mathrm{~kg}$ of commercial MOX fuel was dissolved in boiling $7 \mathrm{M} \mathrm{HNO}_{3}$ which produced $7 \mathrm{~L}$ of fuel solution used as feed for the process. Some characteristics of the original MOX fuel and the fuel solution are given in Tables 1 and 2, respectively.

\section{Concentration-denitration}

For the experiment a one litre round-bottomed three-necked flask, which was placed in a combined heater/magnetic stirrer, was used. The first neck was connected to a glass in-pipe used for feeding solutions using a peristaltic pump. This inpipe led to the bottom of the flask, ensuring that all liquids introduced into the flask entered at the base. The central neck led to a condensing unit, which allowed gas to pass through, but directed the liquid returning from the primary condenser through a second condenser to be collected at the side of the apparatus. The acidic nitrous gases produced in the experiment were collected in three gas-traps filled with $3.5 \mathrm{M} \mathrm{NaOH}$. The third neck was filled with a plastic stopper and was during the experiment used for liquid sampling by pipetting. All liquid samples were analysed by ICP-MS. The nitric acid concentration in the samples was determined by acid-base titration using titration equipment (Metrohm 655 Dosimat).

The process was carried out in two steps: first, concentration by boiling of the HAR solution and later, after separation of precipitates, denitration by dropwise addition of formic acid into the remaining solution. The precipitate composition was analysed by ICPMS after dissolution
Table 1. Characteristics of the original MOX fuel.

\begin{tabular}{lc}
\hline Reactor type & PWR \\
Average burn-up & $30 \mathrm{GWd} / \mathrm{tM}$ \\
Fuel pin diameter & $10.75 \mathrm{~mm}$ \\
Full Power Days & 957 \\
Discharged date & 9.6 .89
\end{tabular}

Table 2. Uranium and plutonium total concentrations and isotopic composition of the fuel solution (by IDMS and TIMS, i.e. isotope dilution and thermal ionisation mass spectrometry).

\begin{tabular}{lccc}
\hline Uranium $[\mathrm{mg} / \mathrm{g}]$ & $114.7 \pm 0.9$ & Plutonium $[\mathrm{mg} / \mathrm{g}]$ & $4.43 \pm 0.02$ \\
\hline \multicolumn{4}{c}{ Isotopic composition (wt. \%) } \\
\hline U-234 & 0.016 & $\mathrm{Pu}-238$ & 2.947 \\
U-235 & 0.375 & $\mathrm{Pu}-239$ & 42.401 \\
U-236 & 0.077 & $\mathrm{Pu}-240$ & 33.562 \\
U-238 & 99.529 & $\mathrm{Pu}-241$ & 10.372 \\
& & $\mathrm{Pu}-242$ & 10.715 \\
\hline
\end{tabular}

in $\mathrm{HNO}_{3}: \mathrm{HCl}(8: 2)$ in pressurised Teflon ${ }^{\circledR}$ containers at $180^{\circ} \mathrm{C}$ for 12 hours.

The concentration factor $(\mathrm{CF})$ for the concentration is defined by the Eq. (1):

$$
\mathrm{CF}=\frac{\text { initial volume of HAR solution }(\mathrm{mL})}{\text { final volume of HAC solution }(\mathrm{mL})} \text {. }
$$

\section{Results and discussion \\ PUREX process}

The PUREX process yielded $9 \mathrm{~L}$ of HAR. The aqueous concentration profile in the extractor battery for some actinides and fission products are shown in Fig. 2. Uranium and plutonium were efficiently extracted. Smaller but significant extraction of neptunium was also observed. Of the fission products technetium and zirconium were co-extracted, as the process was not optimised to direct these elements to the raffinate stream. Americium, curium and the rest of the fission products, including lanthanides (represented in Fig. 2 by La) were not extracted. For stripping $0.01 \mathrm{M}$ nitric acid was used. Uranium and technetium were accumulated in the back-extraction section. Of the actinides, plutonium was the most efficiently stripped. To reach higher recovery rates for uranium, neptunium and technetium the back-extraction has to be optimised in terms of acidity and number of stages.

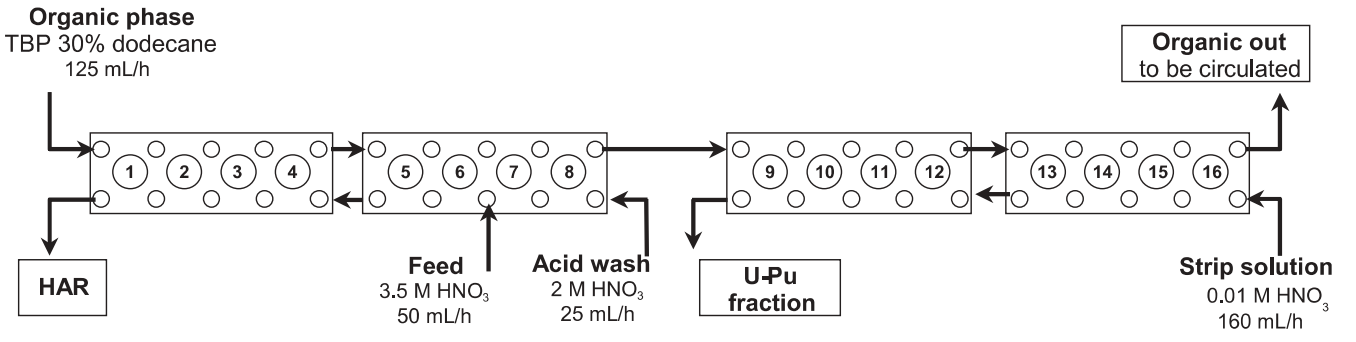

Fig. 1. PUREX process flowsheet for production of HAR. Organic phase is re-circulated after conditioning with $1 \mathrm{M}$ $\mathrm{NaOH}$ followed by acidification. 


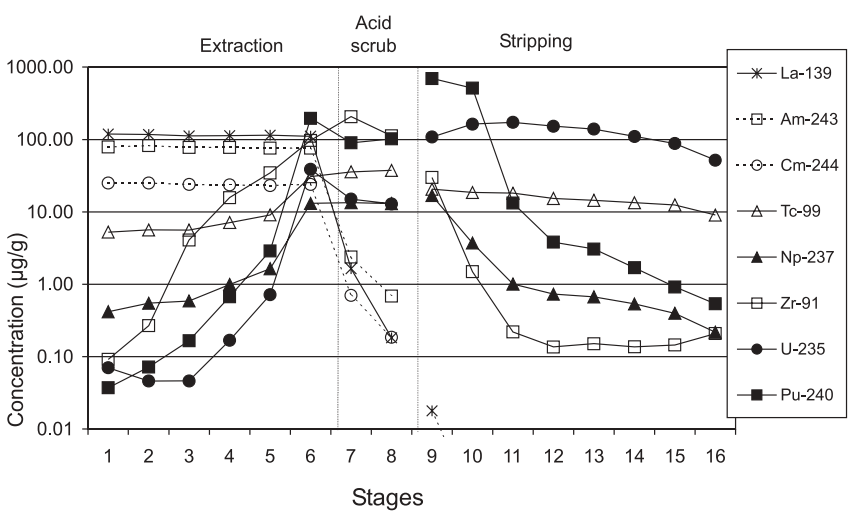

Fig. 2. Aqueous concentration profiles for some representative isotopes of $\mathrm{U}, \mathrm{Pu}, \mathrm{Np}, \mathrm{Tc}, \mathrm{Zr}, \mathrm{La}, \mathrm{Am}$ and $\mathrm{Cm}$. The feed and the acid wash solutions, are introduced in stages 6 and 8 , respectively.

The recoveries in the outgoing fractions as well as decontamination factors for some representative elements are listed in Table 3.

The decontamination factor (DF) for the extraction is defined by the Eq. (2):

$$
\mathrm{DF}=\frac{C_{\text {Feed }} M_{\text {Feed }}}{C_{\text {Raffinate }} M_{\text {Raffinate }}},
$$

where $C$ and $\mathrm{M}$ are component concentration in the solute and mass flow-rate of the solute respectively.

For $\mathrm{U}$ and $\mathrm{Pu} \mathrm{DF}$ values higher than $10^{4}$ and $10^{3}$ respectively were determined. Among the actinides also $\mathrm{Np}$ was extracted to $93 \%$. In addition $\mathrm{Zr}$ and $\mathrm{Tc}$ were also extracted to about $95 \%$ and $70 \%$, respectively, as the flowsheet was not optimised to direct them back to the raffinate stream. All the other lighter fission products and lanthanides, repre- sented in Table 3 by $\mathrm{Cs}$ and La respectively, and MA were completely recovered in the HAR solution.

A characterisation of the produced genuine HAR is shown in Table 4. Due to differences in the process (e.g. fuel-aqueous dissolution ratio, limitation to 16 extractor stages) the concentration of the produced HAR is two times lower than that of an industrial HAR.

\section{Concentration/denitration \\ Optimisation of the process}

A concentration/denitration process using concentrated formic acid is a highly exothermic process that needs extreme care in execution. It is especially of importance to know the induction time and the amount of formic acid needed to safely control the process in order to avoid an uncontrolled reaction that might lead to overboiling or even explosive conditions. This has to be avoided by all means in a hot cell environment using highly radioactive solutions.

In order to establish the best conditions to run the active experiment, several concentration/denitration experiments were carried out at ITU and FZJ (ForschungsZentrum Jülich) [7] using inactive HAR solutions, prepared according to the elemental composition in Table 4. The main selected optimisation criterion, apart from gaining experience in controlling the reaction rate, was to avoid lanthanide precipitation, which can be assumed to behave as the actinides in the genuine HAR.

In all experiments performed precipitation occurred at CFs higher than 6, see Table 5. However, no significant precipitation of lanthanides was found for CF up to 10-12 (less than $0.02 \%$ ), while by increasing the $\mathrm{CF}$ to 14 more than
Table 3. Recoveries (\%) and DF values obtained in the PUREX experiment.

\begin{tabular}{lcccr}
\hline Element & \multicolumn{3}{c}{ Recovery (\%) } & \multirow{2}{*}{ DF } \\
\cline { 2 - 4 } & Org-out sol & U-Pu fraction & HAR & \\
\hline $\mathrm{Zr}$ & $<0.01$ & 96.4 & 3.6 & 26 \\
$\mathrm{Mo}$ & $<0.001$ & $<0.001$ & $>99.999$ & 1 \\
$\mathrm{Tc}$ & 18.8 & 71.1 & 10.0 & 10 \\
$\mathrm{Cs}$ & $<0.001$ & $<0.001$ & $>99.999$ & 1 \\
$\mathrm{La}$ & $<0.001$ & $<0.001$ & $>99.999$ & 1 \\
$\mathrm{~Np}$ & 0.4 & 92.8 & 6.8 & 15 \\
$\mathrm{U}$ & 15.1 & 84.9 & $<0.01$ & $>15000$ \\
$\mathrm{Pu}$ & 0.1 & 99.9 & $<0.01$ & $>20000$ \\
$\mathrm{Am}$ & $<0.001$ & $<0.001$ & $>99.999$ & 1 \\
$\mathrm{Cm}$ & $<0.001$ & $<0.001$ & $>99.999$ & 1 \\
\hline
\end{tabular}

Table 4. Composition of ITU genuine HAR.
HAR concentration $(\mu \mathrm{g} / \mathrm{g})$

\begin{tabular}{lccrcrrr}
\hline $\mathrm{Rb}$ & 22 & $\mathrm{Ag}$ & 9 & $\mathrm{La}$ & 96 & $\mathrm{U}$ & 8 \\
$\mathrm{Sr}$ & 21 & $\mathrm{Cd}$ & 11 & $\mathrm{Ce}$ & 178 & $\mathrm{~Np}$ & 3 \\
$\mathrm{Y}$ & 26 & $\mathrm{In}$ & 2 & $\mathrm{Pr}$ & 83 & $\mathrm{Pu}$ & 1 \\
$\mathrm{Zr}$ & $63^{a}$ & $\mathrm{Sn}$ & 3 & $\mathrm{Nd}$ & 329 & $\mathrm{Am}$ & 344 \\
$\mathrm{Mo}$ & 184 & $\mathrm{Sb}$ & 2 & $\mathrm{Pm}$ & 5 & $\mathrm{Cm}$ & 21 \\
$\mathrm{Tc}$ & $10^{a}$ & $\mathrm{Te}$ & 71 & $\mathrm{Sm}$ & 80 & & \\
$\mathrm{Ru}$ & 128 & $\mathrm{Cs}$ & 368 & $\mathrm{Eu}$ & 18 & & \\
$\mathrm{Rh}$ & 31 & $\mathrm{Ba}$ & 47 & $\mathrm{Gd}$ & 24 & & \\
$\mathrm{Pd}$ & 123 & & & $\mathrm{Dy}$ & 14 & & \\
\hline
\end{tabular}

a: Concentrations would be 264 and $58 \mathrm{mg} / \mathrm{g}$ for $\mathrm{Zr}$ and $\mathrm{Tc}$, respectively, if not extracted in PUREX process. 
Table 5. Summary of inactive concentration/denitration experiments carried out at ITU (1 to 9) and FZJ (10 to 11).

\begin{tabular}{lrcc}
\hline Experiment & CF & Precipitate $(\mathrm{mg})^{a}$ & Precipitation of Ln (\%) \\
\hline 1 & 2 & not significant & - \\
2 & 3 & not significant & - \\
3 & 4 & not significant & - \\
4 & 6 & $<50$ & not significant \\
5 & 8 & 120 & $<0.01$ \\
6 & 9 & 450 & $<0.02$ \\
7 & 9 & 430 & $<0.01$ \\
8 & 11 & 1070 & $<0.01$ \\
9 & 14 & 1530 & 0.3 \\
10 & 9 & 460 & $<0.02$ \\
11 & 14 & 1500 & 0.4 \\
\hline
\end{tabular}

a: from $2 \mathrm{~L}$ initial simulated HAR solution.

$0.3 \%$ of the original lanthanides in solution were found in the precipitate. The precipitate was mainly composed of $\mathrm{Sr}$, Mo, Ag, Sn and Ba.

The precipitation predominantly occurred during the concentration step. For safety reasons and to better understand the precipitation process the influence of removing the precipitate before the denitration step was studied. There- fore, two different experiments (6 and 7) both with a $\mathrm{CF}$ of 9 were carried out. In exp. 6 the precipitate was removed before denitration while in exp. 7 the precipitate remained throughout the complete process. It was noticed that neither the induction time for the denitration nor the composition and amount did change significantly. As a consequence it was decided to run the active test in the hot cell keeping the precipitate in the solution throughout the process

\section{Hot experiment}

Based on these "cold" optimisation experiments a CF of 10 was selected as a final goal for the "hot" concentrationdenitration experiment.

Table 6 summarises the initial parameters and end conditions reached in the experiment. As can be seen a total of 4.06 L HAR was concentrated in 3 days, into $394 \mathrm{~mL}$ HAC, i.e. a CF of 10.2 with a final acidity of $4 \mathrm{M}$. The precipitate, which was formed mainly in the concentration step, was removed from the solution before denitration. The dry weight was about $1.8 \mathrm{~g}$ which is in agreement to the amounts obtained in previous cold tests using similar conditions (CF and final acidity).
Table 6. Initial data and end conditions reached in the concentration/denitration of genuine HAR.

Table 7. Some relevant elemental concentrations, CF and recoveries of the "hot" concentration denitration experiment.

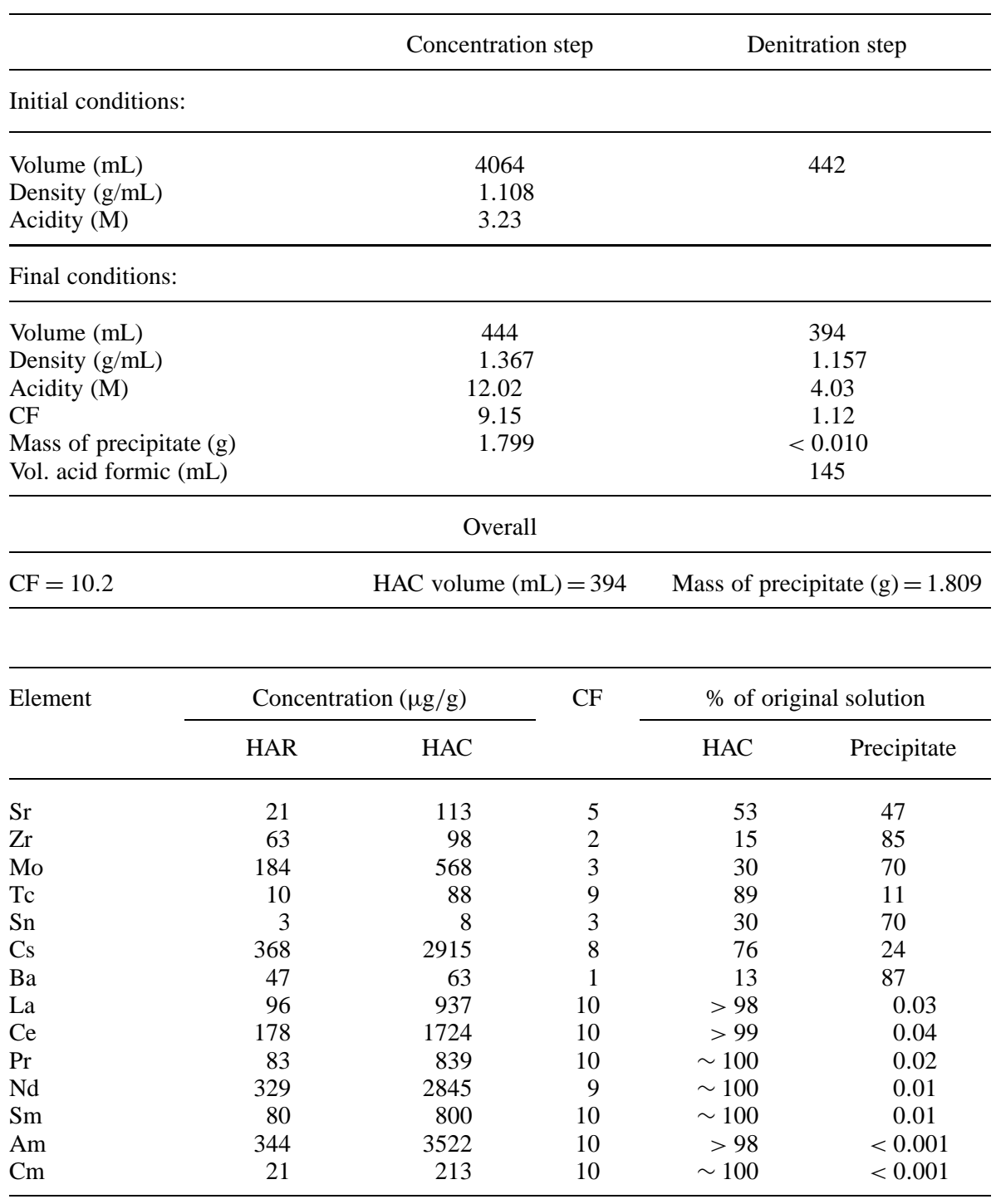


Samples from initial (HAR) and final (HAC) solutions, as well as from the precipitate, were taken and analysed. The results are summarised in Table 7, in which concentrations of all elements analysed are given for the HAC. This has been compared with the concentrations obtained in the initial HAR and the known final concentration factor, 10.2. It can be seen that practically no actinides (less than $0.001 \%$ ) and very little lanthanides (less than $0.04 \%$ ) precipitated, yielding recoveries in solution of about $100 \%$. Only some lighter fission products: $\mathrm{Sr}, \mathrm{Zr}$, Mo, $\mathrm{Sn}$ and Ba significantly precipitated.

The high removal of $\mathrm{Zr}(85 \%)$ and Mo (70\%) from the solution represents an advantage for the next step of the proposed partitioning scheme. It is well known that one of the problems of the DIAMEX process is co-extraction of $\mathrm{Zr}$ and Mo [8]. This phenomenon can be avoided by complexation of these elements with oxalic acid. However, actinides could start precipitating as oxalates if the added concentration of oxalic acid is too high. Any removal of $\mathrm{Zr}$ and Mo in solution during concentration will decrease the amount of oxalic acid to be added in the DIAMEX process and, therefore, simplify its optimisation.

\section{Conclusions}

Nine litres of genuine HAR have been produced by the PUREX processing. The HAR has been characterised and found to be by a factor of two more diluted than industrial HAR.

A concentration-denitration of genuine HAR has been carried out leading to a CF of 10 without significant loses of actinide by precipitation $(<0.001 \%)$.

A precipitate mainly composed by $\mathrm{Sr}, \mathrm{Zr}$, Mo, Sn and $\mathrm{Ba}$ was formed, mainly in the concentration step. The removal of $\mathrm{Zr}(85 \%)$ and $\mathrm{Mo}(90 \%)$ contributes significantly to simplify the following DIAMEX process, where oxalic acid is added to prevent co-extraction of these elements.
Acknowledgment. Part of this study was carried out with CEC financial support under the Fifth Framework Program under Management and Disposal of Radioactive Waste, Contract FIKW-CT2000-00087. The authors acknowledge C. Madic for the co-ordination in this European project called PARTNEW and to P.Baron for the modelling of the PUREX flow sheet.

\section{References}

1. Malmbeck, R., Courson, O., Pagliosa, G., Römer, K., Sätmark, B., Glatz, J.-P., Baron., P.: Partitioning of minor actinides from HLLW using the DIAMEX process. Part 2 - "Hot" continuous counter-current experiment, Radiochim. Acta 88, 865 (2000).

2. Madic, C., Blanc P., Condamines, N., Baron, P., Berthon, L., Nicol, C., Pozo, C., Lecomte, M., Philippe, M., Masson, M., Hequet C., Hudson, M. J.: Actinide partitioning from high active waste using the DIAMEX process. The $4^{\text {th }}$ Int. Conf. on Nuclear Fuel Rep. and Waste Management, RECOD94, London (1994).

3. Sätmark B., Courson O., Malmbeck R., Pagliosa G., Römer K., Glatz, J.-P.: Separation of Minor Actinides from a Genuine MA/Ln Fraction. $6^{\text {th }}$ International Information Exchange Meeting on Actinide and Fission Product Partitioning and Transmutation, Madrid, Dec. 11-13 (2000).

4. Christiansen, B., Apostolidis, C., Carlos, R., Courson, O., Glatz, J.-P., Malmbeck, R., Pagliosa, G., Römer, K., Serrano-Purroy, D.: Advanced aqueous reprocessing in P\&T strategies: Process demonstrations on genuine fuels and targets. Radiochim. Acta 92, 475 (2004).

5. Heits: Zusammensetzung und Herstellung von HAW/HAWC. Simulaten Deutsche Gesellschaft für Wiederaufarbeitung von Kernbrennstoffen (1982).

6. Glatz, J.-P., Song, C., He, X., Bokelund, H., Koch, L.: Partitioning of Actinides from HAW in a Continuous Process by Centrifugal Extractors. (Tedder, D. W., ed.) Special Symposium on Emerging Technologies in Hazardous Waste Management, Atlanta, ACS, Washington DC (1993).

7. Serrano-Purroy, D., Birck, S., Christiansen, B., Glatz, J.- P., Hollas, S., Malmbeck, R., Römer, K., Sheppler, C., Teixeira, E., de Weerd, W., Van Winckel, S.: Towards a DIAMEX process flow sheet using High Active Concentrate (HAC). Proceeding in $7^{\text {th }}$ International Information Exchange Meeting on Actnide and Fission Product P\&T, Jeju, Korea, Oct. 14-16 (2002).

8. Courson, O., Malmbeck, R., Pagliosa, G., Römer, K., Sätmark, B., Glatz, J.-P.: Partitioning of Minor Actinides from HLLW using the DIAMEX process. Part 1 - Demonstration of extraction performances and hydraulic behaviour of the solvent in a continuous process. Radiochim. Acta 88, 857 (2000). 